\title{
Treatment variation in stent choice in patients with stable or unstable coronary artery disease
}

\author{
L.T. Burgers · E.A. McClellan - I.E. Hoefer · G. Pasterkamp • J.W. Jukema · S. Horsman • \\ N.H.J. Pijls · J. Waltenberger $\cdot$ M.A. Hillaert $\cdot$ A.C. Stubbs $\cdot$ J.L. Severens $\cdot$ W.K. Redekop
}

Published online: 13 January 2016

(C) The Author(s) 2016. This article is published with open access at Springerlink.com

\begin{abstract}
Aim Variations in treatment are the result of differences in demographic and clinical factors (e.g. anatomy), but physician and hospital factors may also contribute to treatment variation. The choice of treatment is considered important since it could lead to differences in long-term outcomes. This study explores the associations with stent choice: i.e. drug-eluting stent (DES) versus bare-metal stents (BMS) for Dutch patients diagnosed with stable or unstable coronary artery disease (CAD).

Methods \& results Associations with treatment decisions were based on a prospective cohort of 692 patients with stable or unstable CAD. Of those patients, 442 patients
\end{abstract}

L.T. Burgers $(\bowtie) \cdot$ J.L. Severens · W.K. Redekop

Institute of Health Policy \& Management, and Institute for

Medical Technology Assessment, Erasmus University Rotterdam,

Rotterdam, The Netherlands

e-mail: 1tburgers@gmail.com

E.A. McClellan

Department of Mathematical and Computer Sciences,

Metropolitan State University of Denver,

Colorado, USA

I.E. Hoefer · G. Pasterkamp

Laboratory of Experimental Cardiology, UMC Utrecht,

Utrecht, The Netherlands

J.W. Jukema

Department of Cardiology, Leiden UMC,

Leiden, The Netherlands

S. Horsman · A.C. Stubbs

Department of Bioinformatics, Erasmus Medical Center,

Rotterdam, The Netherlands were treated with BMS or DES. Multiple logistic regression analyses were performed to identify variables associated with stent choice. Bivariate analyses showed that NYHA class, number of diseased vessels, previous percutaneous coronary intervention, smoking, diabetes, and the treating hospital were associated with stent type. After correcting for other associations the treating hospital remained significantly associated with stent type in the stable CAD population. Conclusions This study showed that several factors were associated with stent choice. While patients generally appear to receive the most optimal stent given their clinical characteristics, stent choice seems partially determined by the treating hospital, which may lead to differences in longterm outcomes.

N.H.J. Pijls

Department of Cardiology, Catharina Hospital Eindhoven, Eindhoven, The Netherlands

J. Waltenberger

Department of Cardiology, Maastricht University Medical

Center,

Maastricht, The Netherlands

J. Waltenberger

Department of Cardiovascular Medicine, University of Münster,

Münster, Germany

M.A. Hillaert

Department of Cardiology, University Medical Centre Utrecht, Utrecht, The Netherlands 
Keywords Treatment variation - Coronary artery disease $\cdot$ Drug-eluting stent $\cdot$ Bare-metal stent .

Percutaneous coronary intervention

\section{Introduction}

Despite improvement in the prognosis of patients with cardiovascular disease (CVD) it still remains the second leading cause of death across the Western world and one of the major causes of disability [1]. For many years patients with coronary artery disease (CAD), the most frequent type of CVD, were treated mainly with percutaneous coronary intervention (PCI), coronary artery bypass grafting (CABG) or medication only. Both revascularisations reduce the incidence of death and myocardial infarction (MI) in CAD patients compared with no treatment, but most patients are now treated with PCI. In 2012 approximately 39,000 PCIs were performed in the Netherlands [2]. Originally a PCI was performed with an expanding balloon; however, nowadays patients are often treated with a bare-metal stent (BMS) or drug-eluting stent (DES). DES reduces restenosis compared with BMS (8.4 versus $20.9 \%$ ) [3]. However, patients treated with DES, especially the early-generation, might have a higher chance of developing very late stent thrombosis ( 0.7 versus $0.1 \%$ ) [3]. Both types of stents have pros and cons; decisions should be based on what is considered appropriate for a patient since the choice of stent type may have impact on long-term outcomes. Variations in treatment are the result of differences in patient characteristics and clinical factors (e.g. anatomy) but previous studies have shown that physician and hospital factors may contribute to treatment variation. In the UK, stent choice was associated with the operator and the treating hospital [4]. Tu et al. [5] have shown that the physician performing the diagnostic catheterisation and the treating hospital were strong independent predictors of the type of revascularisation (CABG versus PCI) in Canada. Furthermore, the type of stent was also determined by the type of payer (e.g. Medicaid, private insurance) [6]. Of course, these results may be expected to be healthcare system specific and do not apply for Dutch patients, since the Netherlands has a centrally publicly funded healthcare system.

This study will explore the associations with stent choice (DES or BMS) for Dutch patients diagnosed with stable or unstable $\mathrm{CAD}$ focusing on variation due to clinical factors and treating hospital.

\section{Methods}

Study design

Treatment variation of patients with stable or unstable CAD was explored through analysing data from the Circulating Cells prospective cohort study, which has the aim of discovering markers that identify patients who are at an increased risk of developing a cardiovascular event. In this multicentre study, patients undergoing coronary angiography were included if they had known or suspected stable or unstable $\mathrm{CAD}$; specific diagnoses included unstable angina and nonST-elevation MI (NSTEMI) [7].

\section{Treatment}

Patients undergoing coronary angiography were asked to participate in the study. Data were collected regarding patient characteristics, test results and treatment decisions. Patients who were treated with a PCI received a BMS, DES, drug-eluting balloon angioplasty or standard balloon angioplasty. The aim of this study is to examine the factors that are associated with stent choice (DES vs. BMS), meaning that patients treated solely with drug-eluting balloon angioplasty or standard balloon angioplasty are excluded from the analyses. Stent choice for DES was defined as a PCI with at least one DES, including patients treated with only DES but also patients treated with DES in combination with BMS, drug-eluting balloon angioplasty or standard balloon angioplasty. Stent choice for BMS was defined as a PCI with only BMS such that patients treated with BMS in combination with balloon angioplasty or DES are excluded.

\section{Data and statistical analyses}

Choice of stent type (DES or BMS) was compared between patient subgroups, determined by diagnosis. The following baseline characteristics were also collected during the study: age, gender, body mass index (BMI), systolic blood pressure (SBP), diastolic blood pressure (DBP), thrombolysis in myocardial infarction (TIMI) score for unstable CAD patients, New York Heart Association (NYHA) class, number of diseased vessels (50-99\% stenosis), cardiac history (previous heart failure, previous MI, previous PCI, and previous $\mathrm{CABG}$ ), non-cardiac history (cerebrovascular accident (CVA) or transient ischaemic attack (TIA), pulmonary disease, peripheral vessel disease (PVD), and renal failure), and CVD risk factors (diabetes mellitus, hypertension, hyperlipidaemia, smoking, and pack-years (tobacco)).

Multiple imputation was used to prevent patients from being excluded from the analyses due to missing values. Baseline characteristics (SBP, DBP, BMI, NYHA class, previous heart failure, previous MI, CVA or TIA, pulmonary 
Table 1 Baseline characteristics

\begin{tabular}{|c|c|c|c|c|c|c|c|c|c|c|}
\hline & \multicolumn{3}{|c|}{ All patients after imputation } & \multicolumn{3}{|c|}{ Patients with stable CAD } & \multicolumn{3}{|c|}{ Patients with unstable CAD } & \multirow[t]{2}{*}{$p$ value $^{\mathrm{a}}$} \\
\hline & Mean & $\mathrm{SD}$ & $N^{\mathrm{b}}$ & Mean & SD & $N^{b}$ & Mean & $\mathrm{SD}$ & $N^{\mathrm{b}}$ & \\
\hline \multicolumn{11}{|l|}{ Baseline characteristics } \\
\hline Age & 62.72 & 10 & 442 & 62.96 & 10 & 358 & 61.71 & 11 & 84 & 0.319 \\
\hline Male (\%) & $72 \%$ & & 442 & $73 \%$ & & 358 & $68 \%$ & & 84 & 0.354 \\
\hline $\mathrm{SBP}(\mathrm{mmHg})$ & 135 & 19 & 442 & 135 & 19 & 358 & 134 & 21 & 84 & 0.748 \\
\hline $\mathrm{DBP}(\mathrm{mmHg})$ & 77 & 11 & 442 & 77 & 11 & 358 & 79 & 11 & 84 & 0.273 \\
\hline BMI $\left(\mathrm{kg} / \mathrm{m}^{2}\right)$ & 28 & 4 & 442 & 28 & 4 & 358 & 27 & 4 & 84 & 0.266 \\
\hline \multicolumn{11}{|l|}{ TIMI score } \\
\hline 1 & $8 \%$ & & 83 & & & & $8 \%$ & & 83 & \\
\hline 2 & $18 \%$ & & 83 & & & & $18 \%$ & & 83 & \\
\hline 3 & $30 \%$ & & 83 & & & & $30 \%$ & & 83 & \\
\hline 4 & $28 \%$ & & 83 & & & & $28 \%$ & & 83 & \\
\hline 5 & $12 \%$ & & 83 & & & & $12 \%$ & & 83 & \\
\hline $6+7$ & $4 \%$ & & 83 & & & & $4 \%$ & & 83 & \\
\hline \multicolumn{4}{|c|}{ Number of diseased vessels (50-99\%) } & & & & & & & 0.077 \\
\hline 1 & $44 \%$ & & 442 & $46 \%$ & & 358 & $36 \%$ & & 84 & \\
\hline$>1$ & $56 \%$ & & 442 & $54 \%$ & & 358 & $64 \%$ & & 84 & \\
\hline NYHA & & & & & & & & & & $p<0.001$ \\
\hline NYHA I & $73 \%$ & & 442 & $73 \%$ & & 358 & $76 \%$ & & 84 & \\
\hline NYHA II & $18 \%$ & & 442 & $20 \%$ & & 358 & $7 \%$ & & 84 & \\
\hline NYHA III & $6 \%$ & & 442 & $7 \%$ & & 358 & $4 \%$ & & 84 & \\
\hline NYHA IV & $2 \%$ & & 442 & $0 \%$ & & 358 & $13 \%$ & & 84 & \\
\hline \multicolumn{11}{|l|}{ Cardiac history (\%) } \\
\hline Previous heart failure & $2 \%$ & & 442 & $2 \%$ & & 358 & $1 \%$ & & 84 & 0.542 \\
\hline Previous MI & $31 \%$ & & 442 & $33 \%$ & & 358 & $23 \%$ & & 84 & 0.066 \\
\hline Previous PTCA & $33 \%$ & & 442 & $35 \%$ & & 358 & $26 \%$ & & 84 & 0.116 \\
\hline Previous CABG & $7 \%$ & & 442 & $8 \%$ & & 358 & $5 \%$ & & 84 & 0.369 \\
\hline \multicolumn{11}{|l|}{ Non-cardiac history (\%) } \\
\hline CVA/TIA & $8 \%$ & & 442 & $6 \%$ & & 358 & $14 \%$ & & 84 & 0.017 \\
\hline Pulmonary disease & $11 \%$ & & 442 & $10 \%$ & & 358 & $14 \%$ & & 84 & 0.242 \\
\hline Peripheral vessel disease & $13 \%$ & & 442 & $13 \%$ & & 358 & $14 \%$ & & 84 & 0.684 \\
\hline Renal failure & $3 \%$ & & 442 & $4 \%$ & & 358 & $1 \%$ & & 84 & 0.25 \\
\hline \multicolumn{11}{|l|}{ Risk factors (\%) } \\
\hline Diabetes mellitus & $21 \%$ & & 442 & $22 \%$ & & 358 & $20 \%$ & & 84 & 0.764 \\
\hline Hypertension & $66 \%$ & & 442 & $67 \%$ & & 358 & $60 \%$ & & 84 & 0.189 \\
\hline Hyperlipidaemia & $68 \%$ & & 442 & $70 \%$ & & 358 & $60 \%$ & & 84 & 0.057 \\
\hline Current smokers & $19 \%$ & & 442 & $16 \%$ & & 358 & $32 \%$ & & 84 & 0.001 \\
\hline Pack years $^{\mathrm{d}}$ & 19.7 & 18 & 442 & 19.2 & 18.1 & 358 & 21.9 & 22.1 & 84 & 0.302 \\
\hline \multicolumn{11}{|l|}{ Diagnosis (\%) } \\
\hline Stable angina & $81 \%$ & & 442 & & & & & & & \\
\hline Unstable angina & $10 \%$ & & 442 & & & & & & & \\
\hline NSTEMI & $9 \%$ & & 442 & & & & & & & \\
\hline Treatment/stent choice & & & & & & & & & & 0.736 \\
\hline DES & $66 \%$ & & 442 & $66 \%$ & & 358 & $68 \%$ & & 84 & \\
\hline BMS & $34 \%$ & & 442 & $34 \%$ & & 358 & $32 \%$ & & 84 & \\
\hline \multicolumn{11}{|l|}{ Hospital } \\
\hline I & $29 \%$ & & 442 & $28 \%$ & & 358 & $37 \%$ & & 84 & \\
\hline II & $22 \%$ & & 442 & $24 \%$ & & 358 & $13 \%$ & & 84 & \\
\hline III & $18 \%$ & & 442 & $14 \%$ & & 358 & $37 \%$ & & 84 & \\
\hline IV & $30 \%$ & & 442 & $34 \%$ & & 358 & $13 \%$ & & 84 & \\
\hline
\end{tabular}

$B M I$ body mass index, $C A B G$ coronary artery bypass graft, $C V A$ cerebrovascular accident, $D B P$ diastolic blood pressure, $M I$ myocardial infarction, NA not applicable, NSTEMI non ST elevation myocardial infarction, NYHA New York heart association, PTCA percutaneous transluminal coronary angioplasty, $S B P$ systolic blood pressure, TIA transient ischaemic attack, TIMI thrombolysis in myocardial infarction.

${ }^{\text {a }}$ Stable versus unstable.

${ }^{b}$ Number of patients on which the analyses were based.

${ }^{\mathrm{c}}$ Only reported for unstable angina and NSTEMI.

${ }^{\mathrm{d}}$ Number of packs per day multiplied with years of smoking. 
disease, PVD, renal failure, diabetes mellitus, hypertension, hyperlipidaemia, current smoker and pack-years) were missing for less than $2 \%$ of all cases except pack-years, which was missing for $14 \%$ of all cases. These characteristics were imputed using predictive mean matching for scale variables. Five imputation sets were created with ten iterations, each using fully conditional specification in SPSS 22 (IBM Corp. Released 2013. IBM SPSS Statistics for Windows, Version 22.0. Armonk, NY: IBM Corp). Age, gender, previous PCI, previous $\mathrm{CABG}$, and diagnosis were only used as predictors and not imputed since there were no missing values for these variables.

Differences between groups were tested using Chisquared analysis for categorical variables. Bivariate analyses using logistic regression were performed to identify variables that were associated with stent type; stable and unstable CAD patients were analysed separately. Backwards selection was used to create the final multivariate model(s). P values lower than 0.05 were considered statistically significant, although a higher threshold of 0.1 was used to select variables for the multivariate analysis. Associations were discussed with clinical experts in order to see if the results make sense (face validity).

\section{Results}

In total, 714 patients were included in the Circulating Cells cohort, 22 of whom were excluded from the analyses since they did not have significant coronary atherosclerosis. The remaining 692 patients were included in three teaching hospitals and one general hospital, and 477 patients were treated with PCI. Of those patients, 442 patients were treated with BMS or DES. Others were treated with a combination of BMS and balloon angioplasty $(n=4)$, drug-eluting balloon angioplasty or standard balloon angioplasty $(n=18)$ or missing $(n=13)$ and are excluded from the analysis. The number of patients treated per hospital (I-IV) was 130, 98, 81, and 133 , respectively. Table 1 presents the baseline demographic and angiographic characteristics of the included patients. The mean age of the cohort was 63 years and $72 \%$ were male. The majority $(81 \%)$ of the patients were diagnosed with stable CAD (including silent ischaemia) after the coronary angiography. There were three significant differences in characteristics of stable CAD $(n=358)$ and unstable CAD patients $(n=84)$. Stable CAD patients more often had a lower NYHA class, were less often current smokers and had less often experienced a CVA/TIA compared with unstable CAD patients.

In total 771 stents were used to treat 442 patients with 612 target lesions. On average 1.385 target lesions were stented per patient (range 1-3), where 1.260 stents were used per lesion and 1.744 stents (range 1-6) per patient were used.
Of the 442 patients, $66 \%$ were treated with one or more DES. Bivariate analyses (Table 2) showed that NYHA class, number of diseased vessels, previous PCI, smoking, diabetes and the treating hospital were significantly associated with stent choice for a patient. The frequency of DES use varied widely (50-99\%) between the four hospitals, considering the total population. The variation in stent choice was larger in the unstable patient group (45-100\%).

All multivariate analyses (Table 3) showed that patients with diabetes had a significantly higher chance of receiving DES. The use of DES versus BMS in the stable CAD population was not only associated with diabetes but also with the treating hospital, smoking status, and previous PCI. Patients treated in hospital II or III, patients having diabetes, and patients with a previous PCI had a higher chance of being treated with DES. Patients treated in hospital I and patients who were current smokers had a lower chance of being treated with DES.

\section{Discussion}

This study explored the factors associated with stent choice for Dutch patients diagnosed with stable or unstable CAD. Various factors are associated with the frequency of DES use, including diabetes, previous PCI, number of diseased vessels, NYHA class, smoking and the treating hospital.

Patients requiring a PCI were in most cases treated with at least one DES (66\%), which is in line with the guidelines that suggest that patients with stable CAD should receive a DES if there is no contraindication of prolonged dual antiplatelet therapy [8]. Furthermore, DES is recommended over BMS in NSTEMI or unstable angina patients with diabetes [9]. Since patients with diabetes have a higher restenosis risk than patients without diabetes, DES is considered the most optimal treatment for these patients since DES reduces restenosis compared with BMS. Consequently, diabetes was significantly associated with stent choice in this study. Patients who have been treated before with a PCI were also more likely to receive DES (76\%); these patients have a higher risk of developing restenosis and thus DES was preferred. Patients with multi-vessel disease $(73 \%$ DES) and patients with a high NYHA class (range I-IV: $62-90 \%$ DES) were significantly more frequently treated with DES. Studies suggest that patients with multi-vessel disease should be treated with CABG or PCI using DES since these interventions have shown to be more effective than BMS [10]. Patients currently smoking were less often treated with DES.

These clinical factors can be considered as legitimate leading to variation in stent choice. However, $19 \%$ of the variation in stent choice was explained by these factors in the stable CAD population. Beside clinical factors, other 
Table 2 Associations with therapeutic decision (DES vs BMS)

\begin{tabular}{|c|c|c|c|c|c|c|c|c|c|}
\hline & \multicolumn{3}{|l|}{ All patients } & \multicolumn{3}{|c|}{ Patients with stable CAD } & \multicolumn{3}{|c|}{ Patients with unstable CAD } \\
\hline & DES $(\%) /$ OR & $N$ & $p$ value & DES $(\%) /$ OR & $N$ & $p$ value & DES $(\%) /$ OR & $N$ & $p$ value \\
\hline Overall & $66 \%$ & 442 & & $66 \%$ & 358 & & $68 \%$ & 84 & \\
\hline Diagnosis & & & 0.558 & & & & & & \\
\hline Stable CAD & $66 \%$ & 358 & & & & & & & \\
\hline Unstable angina & $63 \%$ & 46 & & & & & & & \\
\hline NSTEMI & $74 \%$ & 38 & & & & & & & \\
\hline Hospital & & & $p<0.001$ & & & $p<0.001$ & & & $p<0.001$ \\
\hline 1 & $50 \%$ & 130 & & $52 \%$ & 99 & & $45 \%$ & 31 & \\
\hline 2 & $64 \%$ & 98 & & $66 \%$ & 87 & & $55 \%$ & 11 & \\
\hline 3 & $99 \%$ & 81 & & $98 \%$ & 50 & & $100 \%$ & 31 & \\
\hline 4 & $64 \%$ & 133 & & $65 \%$ & 122 & & $55 \%$ & 11 & \\
\hline \multicolumn{10}{|l|}{ Baseline characteristics } \\
\hline Age (years) & 1.008 & 442 & 0.387 & 1.005 & 358 & 0.682 & 1.023 & 84 & 0.272 \\
\hline Gender & & & 0.474 & & & 0.46 & & & 0.872 \\
\hline Male & $67 \%$ & 318 & & $67 \%$ & 261 & & $68 \%$ & 57 & \\
\hline Female & $64 \%$ & 124 & & $63 \%$ & 97 & & $67 \%$ & 27 & \\
\hline $\mathrm{SBP}(\mathrm{mmHg})$ & 1.007 & 442 & 0.188 & 1.003 & 358 & 0.598 & 1.022 & 84 & 0.074 \\
\hline DBP (mmHg) & 0.998 & 442 & 0.815 & 0.997 & 358 & 0.767 & 1.001 & 84 & 0.968 \\
\hline BMI $\left(\mathrm{kg} / \mathrm{m}^{2}\right)$ & 1.038 & 442 & 0.128 & 1.049 & 358 & 0.08 & 0.994 & 84 & 0.912 \\
\hline TIMI score ${ }^{\mathrm{a}}$ & & & 0.085 & & & & & & 0.085 \\
\hline 1 & $71 \%$ & 7 & & & & & $71 \%$ & 7 & \\
\hline 2 & $80 \%$ & 15 & & & & & $80 \%$ & 15 & \\
\hline 3 & $48 \%$ & 25 & & & & & $48 \%$ & 25 & \\
\hline 4 & $83 \%$ & 23 & & & & & $83 \%$ & 23 & \\
\hline 5 & $60 \%$ & 10 & & & & & $60 \%$ & 10 & \\
\hline $6+7$ & $100 \%$ & 3 & & & & & $100 \%$ & 3 & \\
\hline NYHA & & & $p<0.01$ & & & 0.036 & & & 0.011 \\
\hline NYHA I & $62 \%$ & 324 & & $63 \%$ & 260 & & $59 \%$ & 64 & \\
\hline NYHA II & $71 \%$ & 79 & & $69 \%$ & 73 & & $100 \%$ & 6 & \\
\hline NYHA III \& IV & $90 \%$ & 39 & & $88 \%$ & 25 & & $93 \%$ & 14 & \\
\hline $\begin{array}{l}\text { Number of diseased } \\
\text { vessels }\end{array}$ & & & $p<0.01$ & & & $p<0.01$ & & & 0.102 \\
\hline 1 & $58 \%$ & 196 & & $58 \%$ & 166 & & $57 \%$ & 30 & \\
\hline$>1$ & $73 \%$ & 246 & & $72 \%$ & 192 & & $74 \%$ & 54 & \\
\hline \multicolumn{10}{|l|}{ Cardiac history } \\
\hline Previous heart failure & & & 0.981 & & & 0.836 & & & 0.489 \\
\hline Yes & $67 \%$ & 9 & & $63 \%$ & 8 & & $100 \%$ & 1 & \\
\hline No & $66 \%$ & 433 & & $66 \%$ & 350 & & $67 \%$ & 83 & \\
\hline Previous MI & & & 0.077 & & & 0.090 & & & 0.536 \\
\hline Yes & $72 \%$ & 137 & & $72 \%$ & 118 & & $74 \%$ & 19 & \\
\hline No & $64 \%$ & 305 & & $63 \%$ & 240 & & $66 \%$ & 65 & \\
\hline Previous PTCA & & & $p<0.01$ & & & $p<0.01$ & & & 0.271 \\
\hline Yes & $76 \%$ & 148 & & $76 \%$ & 126 & & $77 \%$ & 22 & \\
\hline No & $61 \%$ & 294 & & $60 \%$ & 232 & & $65 \%$ & 62 & \\
\hline Previous CABG & & & 0.541 & & & 0.736 & & & 0.433 \\
\hline Yes & $61 \%$ & 31 & & $63 \%$ & 27 & & $50 \%$ & 4 & \\
\hline No & $67 \%$ & 411 & & $66 \%$ & 331 & & $69 \%$ & 80 & \\
\hline \multicolumn{10}{|l|}{ Non-cardiac history } \\
\hline CVA/TIA & & & 0.748 & & & 0.682 & & & 0.924 \\
\hline Yes & $69 \%$ & 35 & & $70 \%$ & 23 & & $67 \%$ & 12 & \\
\hline No & $66 \%$ & 407 & & $66 \%$ & 335 & & $68 \%$ & 72 & \\
\hline Pulmonary disease & & & 0.103 & & & 0.142 & & & 0.445 \\
\hline Yes & $56 \%$ & 47 & & $55 \%$ & 35 & & $58 \%$ & 12 & \\
\hline No & $68 \%$ & 395 & & $36 \%$ & 323 & & $69 \%$ & 72 & \\
\hline
\end{tabular}


Table 2 (continued)

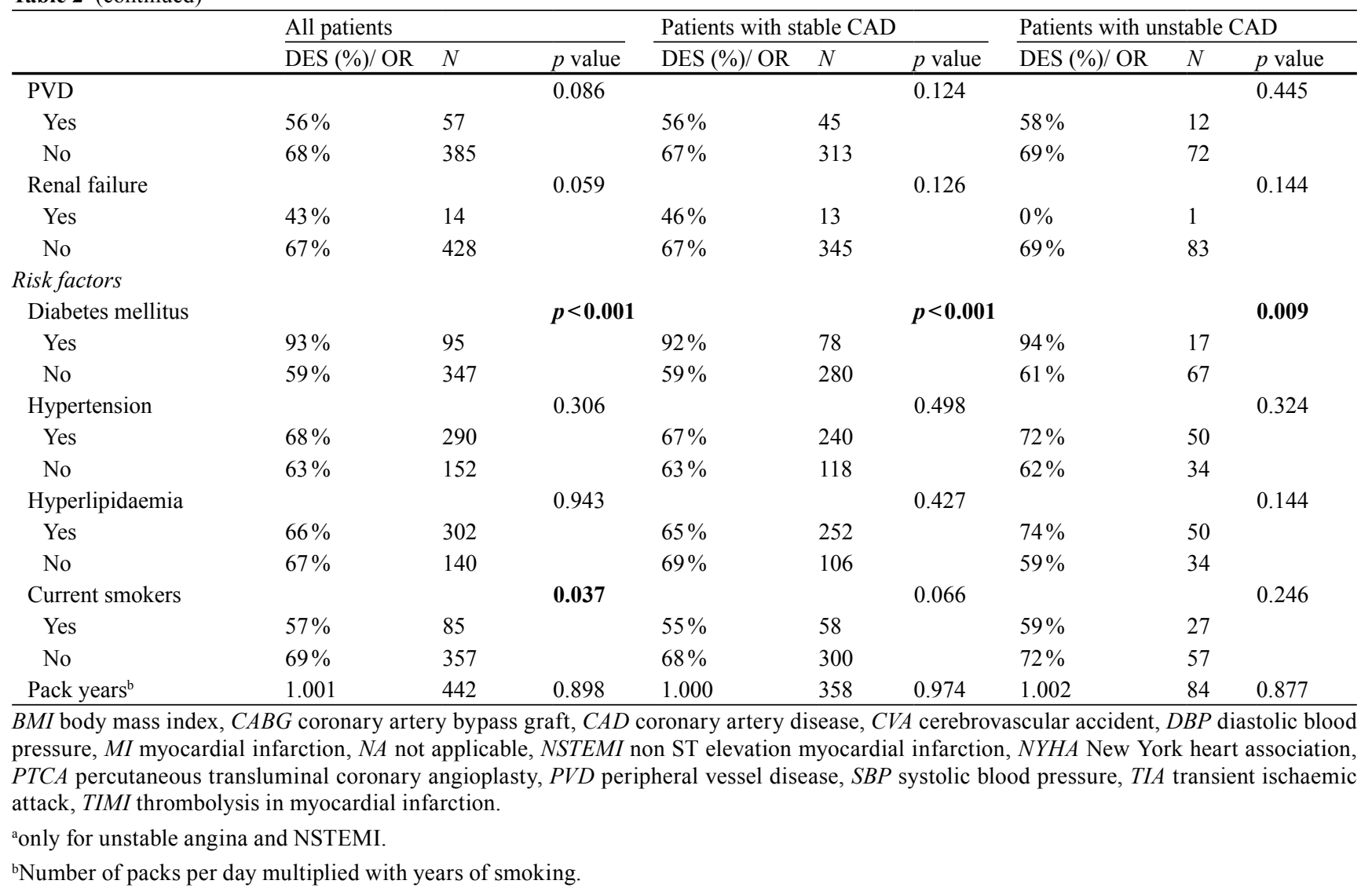

potential reasons for treatment variation could exist due to: (1) the operator, (2) the availability and supply of resources, or (3) patient preferences. Considering operator variation, physicians use different methods to decide which stent is most suited for a particular patient. It is known that some physicians are believers of DES and some do not believe in the added value of DES compared with BMS, while BMS is less expensive. In several randomised clinical trials, DES has shown to be more effective than BMS for several indications (e.g. diabetes, long lesions). Some operators strictly follow the results of these trials and the guidelines while other operators also use DES for other indications with a high restenosis risk since guidelines do not provide recommendations concerning the most optimal stent for every type of patient, although it is probably unrealistic to expect this. In our study, one hospital treated almost all patients with DES (99\%); probably DES was used also for 'off-label' indications. A Dutch report concluded that world-wide DES is used off-label in $47-81 \%$ of the patients, leading to differences in safety and clinical effectiveness [11]. The second potential reason, availability and supply of resources, focuses on the hospital level. In our analyses, the treating hospital was significantly associated with stent choice even after correcting for clinical factors in the stable CAD group.
After adding treating hospital to the regression analysis $33 \%$ of the variation in stent choice could be explained. The analyses showed that the frequency of DES use ranged from $50-99 \%$ of all patients across hospitals. This difference could result from a difference in patient case mix, despite the adjustment for many individual patient characteristics in the analyses. Furthermore, payment arrangements with stent manufacturers and budget constraints may have influenced the stent choice. Another potential reason, patient preference, could have influenced the variation in stent choice. However, we expect this to be minimal since both interventions can be considered to be equally invasive.

Implications

In general, patients receive the most optimal stent given their clinical characteristics. However, stent choice is also determined by the treating hospital, probably due to operator variation and availability and supply of resources. Variation should only occur due to demographic and angiographic factors. When variation is due to factors other than demographics or angiography findings it could lead to less optimal stent choices and subsequently differences in longterm outcomes. 
Table 3 Multivariate analyses therapeutic decision (BMS vs DES)

Bivariate analyses $(\mathrm{OR})$

Multivariate analyses (OR)

$p$ value*

Total population $(n=442)$

Number of diseased vessels

1

0.520

0.560

0.006

$>1$

Ref

Ref

NYHA class

NYHA class II

1.478

NYHA class III+IV

5.311

Hospital

1
2
3
4
Diabetes (yes vs no)

0.565

1.016

45.176

Ref

8.680

0.368

0.599

1.486

1.017

2.045

Previous PTCA (yes vs no)

Ref

1.20

0.37

2.000

0.600

646189937

$6+7$

Constant

Nagelkerke $\mathrm{R}^{2}$

Stable CAD $(n=358)$

BMI $\left(\mathrm{kg} / \mathrm{m}^{2}\right)$

Hospital

1
2
3
4
Previous MI (yes vs no)

Bivariate
1.049

0.578
1.034
26.671
Ref
1.513

1.911

$\mathrm{p}<0.001$

$16 \%$

Multivariate analyses (OR)

$p$ value*

Bivariat

8.318

$\mathrm{p}<0.001$

NYHA class

NYHA class I

Ref

NYHA class II

1.280

NYHA class III+IV

4.319

Number of diseased vessels

$\begin{array}{ll}1 & 0.536 \\ >1 & \text { Ref } \\ \text { Current smoker (yes vs no) } & 0.588 \\ \text { Diabetes (yes vs no) } & 8.454 \\ \text { Previous PTCA (yes vs no) } & 2.103\end{array}$

0.536

0.588

8.454

0.404

0.014

12.001

$\mathrm{p}<0.001$

2.284

0.003

1.207

0.397

Nagelkerke $\mathrm{R}^{2}$

Unstable CAD $(n=84)$

$33 \%$

Bivariate analyses (OR)

Multivariate analyses (OR)

p value*

0.686

1.000

1346229036

Ref 
Table 3 (continued)

\begin{tabular}{|c|c|c|c|}
\hline & Bivariate analyses (OR) & Multivariate analyses (OR) & $p$ value* \\
\hline \multicolumn{4}{|l|}{ NYHA class } \\
\hline NYHA class I & Ref & & \\
\hline NYHA class II & 1105324892 & & \\
\hline NYHA class III+IV & 8.895 & & \\
\hline Diabetes (yes vs no) & 10.146 & 10.146 & 0.029 \\
\hline \multicolumn{4}{|l|}{ TIMI score ${ }^{\mathrm{a}}$} \\
\hline 1 & Ref & & \\
\hline 2 & 1.600 & & \\
\hline 3 & 0.369 & & \\
\hline 4 & 1.900 & & \\
\hline 5 & 0.600 & & \\
\hline $6+7$ & 646189937 & & \\
\hline $\mathrm{SBP}(\mathrm{mmHg})$ & 1.007 & & \\
\hline Constant & & 1.577 & 0.069 \\
\hline Nagelkerke $R^{2}$ & & $13 \%$ & \\
\hline \multicolumn{4}{|c|}{$\begin{array}{l}\text { SBP systolic blood pressure, } B M I \text { body mass index, } N Y H A \text { New York heart association, } P T C A \text { percutaneous transluminal coronary angioplasty, } \\
\text { TIMI Thrombolysis In Myocardial Infarction. }\end{array}$} \\
\hline \multicolumn{4}{|c|}{ aP value of multivariate analyses. } \\
\hline$* p=0.05$ & & & \\
\hline
\end{tabular}

Patients receiving DES have a lower risk of target lesion revascularisation than patients treated with BMS [3]. However, there is some concern of late stent thrombosis that may occur more frequently after DES than BMS [3]. Besides the implications of treatment variation on the effectiveness, it is also important to consider the costs. While BMS is less expensive than DES, BMS leads to more reinterventions than DES. Several studies have estimated the cost-effectiveness of DES versus BMS and many of these studies concluded that initial DES treatment was overall more expensive than the BMS strategy [12-23]; the reduction in reinterventions did not offset the initial higher stent costs. In most of the studies DES was slightly more effective [1223] often leading to an incremental cost-effectiveness ratio that could not be considered cost-effective $[13,14,17,18$, 23]. However, some specific subgroups (diabetes, complex lesions, complex vessels, multi-vessel disease, or a combination of these risk factors) were identified in which DES resulted in a higher health gain in terms of quality-adjusted life-years compared with subgroups that were not at high risk of restenosis and complications. Consequently, in these subgroups, DES was considered more cost-effective. In our study some of these specific subgroups were also associated with a more frequent use of DES.

\section{Limitations}

The factors examined in the analyses explained 13-33\% of the variation in treatment decisions. While the treating hospital was associated with stent choice, it is possible that hospital is a proxy for a pre-existing patient case mix. Many clinical factors were included in the regression models but it is possible that factors that are of predictive value were not included. Furthermore, the underlying reason why the treating hospital is associated with stent choice is unknown. This could be due to the operator (e.g. experience), for which data were not available for our analyses, or the availability and supply of resources might explain the association with the treating hospital, even though the Netherlands has a centrally publicly funded healthcare system.

We were not able to compare patients treated solely with BMS and patients treated solely with DES. Stent choice for DES was defined as a PCI with at least one DES which includes patients treated with only DES but also patients treated with DES in combination with BMS, drug-eluting balloon angioplasty or standard balloon angioplasty. Consequently, the associations that we have found actually explain why some patients receive DES and why other patients did not receive DES.

In addition, this study did not take into consideration the differences in stent choice (different types of DES) despite variation in their effectiveness. For example, the newer ultra-thin strut BMS leads to less restenosis than the thicker strut BMS; a study using the SOLSTICE registry showed that ultra-thin strut BMS leads to low 6-month major adverse cardiac event rates (5.8\%), including target lesion revascularisations [24]. Furthermore, we made no distinction between the types of drug coating (e.g. paclitaxel, sirolimus, or everolimus) used for DES, even though this may affect clinical outcomes.

Lastly, the latest guideline on myocardial revascularisation [25] concluded that the newer generation DES have improved safety outcomes including death, MI and stent thrombosis compared with early-generation DES and BMS. 
During this study, this guideline was not available and thus it is possible that stent choice might have been somewhat different if the new guidelines had been applicable; DES could be more frequently used. Furthermore, we did not focus on fully bioresorbable stents, which have promising clinical outcomes since they provide desirable transient vessel support without compromising the restoration of normal vessel biology, vessel imaging or treatment options in the long run [26]. Consequently, the stents evaluated in the Circulating Cells cohort may not reflect the stent choices that will be made in the near future.

\section{Recommendations}

This study showed the existence of treatment variation across hospitals that may have an impact on long-term outcomes. It would be interesting to investigate if the treatment variation seen in this cohort will actually lead to differences in long-term outcomes and costs, which could be achieved by increasing the follow-up period. Van der Sijde et al. [27] have also emphasised the role of clinical observations to determine the most appropriate indication for specific types of stents.

\section{Conclusions}

This study showed that several clinical factors were associated with stent choice (DES or BMS) for CAD treatment, including diabetes, smoking, NYHA class, multi-vessel disease and previous PCI. In general, it appears that patients receive the most optimal stent given their clinical characteristics. After correcting for the clinical factors, stent choice was also associated with the treating hospital probably due to operator variation and the availability and supply of specific stent types. These differences may lead differences in long term outcomes.

Financial support This work was supported by unrestricted grants from the Center for Translational Molecular Medicine (CTMM), Circulating Cells project (grant 01C-102) and the Dutch Heart Foundation.

Conflicts of interest The authors have no conflicts of interest to declare.

Open Access This article is distributed under the terms of the Creative Commons Attribution License which permits any use, distribution, and reproduction in any medium, provided the original author(s) and the source are credited.

\section{References}

1. Vaartjes I, Koopman C, Dis I van, Visseren F, Bots M. Hart- en vaatziekten in Nederland. 2013. https://www.hartstichting.nl/ downloads/cijferboek-2013, 2014.
2. Heer F de, Groenwold R, ter Burg W, Versteegh M, Herwerden L van, Brinkman E. Openhartoperaties en percutane coronaire interventies bij patienten met hartziekten in Nederland. 2013. https:// www.hartstichting.nl/downloads/cijferboek-2013. Accessed 2013.

3. Roukoz H, Bavry AA, Sarkees ML, et al. Comprehensive metaanalysis on drug-eluting stents versus bare-metal stents during extended follow-up. Am J Med. 2009;122:581. e1.

4. Austin D, Oldroyd KG, McConnachie A, et al. Hospital and operator variations in drug-eluting stent use: a multi-level analysis of 5967 consecutive patients in Scotland. J Public Health (Oxf). 2008;30:186-93.

5. Tu JV, Ko DT, Guo H, et al. Determinants of variations in coronary revascularization practices. CMAJ. 2012;184:179-86.

6. Epstein AJ, Ketcham JD, Rathore SS, Groeneveld PW. Variations in the use of an innovative technology by payer: the case of drugeluting stents. Med Care. 2012;50:1-9.

7. Hoefer IE, Sels JW, Jukema JW, et al. Circulating cells as predictors of secondary manifestations of cardiovascular disease: design of the CIRCULATING CELLS study. Clin Res Cardiol. 2013;102:847-56.

8. Task Force Members, Montalescot G, Sechtem U, Achenbach S, et al. 2013 ESC guidelines on the management of stable coronary artery disease: the Task Force on the management of stable coronary artery disease of the European Society of Cardiology. Eur Heart J. 2013;34:2949-3003.

9. Hamm CW, Bassand JP, Agewall S, et al. ESC Guidelines for the management of acute coronary syndromes in patients presenting without persistent ST-segment elevation: the Task Force for the management of acute coronary syndromes (ACS) in patients presenting without persistent ST-segment elevation of the European Society of Cardiology (ESC). Eur Heart J. 2011;32:2999-3054.

10. Klein LW. Are drug-eluting stents the preferred treatment for multivessel coronary artery disease? J Am Coll Cardiol. 2006;47:22-6.

11. RIVM. Off-label use of coronary drug-eluting stents. Occurrence, safety, and effectiveness in 'real world' clinical practice. 2011. http://www.rivm.nl/en/Documents_and_publications/Scientific/ Reports/2012/juni/Off_label_use_of_coronary_drug_eluting stents_Occurrence_safety_and_effectiveness_in_real_world_clinical_practice, 2015.

12. Hill R, Bagust A, Bakhai A, Dickson R, Dundar Y, Haycox A. Coronary artery stents: a rapid systematic review and economic evaluation. Health Technol Assess. 2004;8:1-256.

13. Hill RA, Boland A, Dickson R, et al. Drug-eluting stents: a systematic review and economic evaluation. Health Technol Assess. 2007;11:1-242.

14. Bischof M, Briel M, Bucher HC, Nordmann A. Cost-effectiveness of drug-eluting stents in a us medicare setting: a cost-utility analysis with 3-year clinical follow-up data. Value Health. 2009;12:649-56.

15. Ekman M, Sjogren I, James S. Cost-effectiveness of the Taxus paclitaxel-eluting stent in the Swedish healthcare system. Scand Cardiovasc J. 2006;40:17-24.

16. Goeree R, Bowen JM, Blackhouse G, et al. Economic evaluation of drug-eluting stents compared with bare metal stents using a large prospective study in Ontario. Int J Technol Assess Healthcare. 2009;25:196-207.

17. Bowen J, Hopkins R, He Y, et al. Systematic review and costeffectiveness analysis of drug eluting stents compared with bare metal stents for percutaneous coronary interventions in Ontario. Interim Report for the Ontario Ministry of Health and Long-term Care. 2005:170.

18. Kuukasjarvi P, Rasanen P, Malmivaara A, Aronen P, Sintonen H. Economic evaluation of drug-eluting stents: a systematic literature review and model-based cost-utility analysis. Int J Technol Assess Healthcare. 2007;23:473-9. 
19. Remak E, Manson S, Hutton J, Brasseur P, Olivier E, Gershlick A. Cost-effectiveness of the Endeavor stent in de novo native coronary artery lesions updated with contemporary data. EuroIntervention. 2010;5:826-32.

20. Shrive FM, Manns BJ, Galbraith PD, Knudtson ML, Ghali WA. Economic evaluation of sirolimus-eluting stents. CMAJ. 2005;172:345-51.

21. Mahieu J, Ridder A de, Graeve D de, Vrints C, Bosmans J. Economic analysis of the use of drug-eluting stents from the perspective of Belgian healthcare. Acta Cardiol. 2007;62:355-65.

22. Mittmann N, Brown A, Seung SJ, et al. Drug eluting stents: an economic evaluation [Technology overview no 15]. Ottawa: Canadian Coordinating Office for Health Technology Assessment; 2005. p 10.

23. Neyt M, De Laet C, De Ridder A, Van Brabandt H. Cost effectiveness of drug-eluting stents in belgian practice healthcare payer perspective. Pharmacoeconomics. 2009;27:313-27.
24. Suttorp MJ, Stella PR, Dens J, et al. Ultra-thin strut cobalt chromium bare metal stent usage in a complex real-world setting. (SOLSTICE registry). Neth Heart J. 2015;23:124-9.

25. Authors/Task Force members, Windecker S, Kolh P, Alfonso F, et al. 2014 ESC/EACTS Guidelines on myocardial revascularization: The Task Force on Myocardial Revascularization of the European Society of Cardiology (ESC) and the European Association for Cardio-Thoracic Surgery (EACTS)Developed with the special contribution of the European Association of Percutaneous Cardiovascular Interventions (EAPCI). Eur Heart J. 2014;35:2541-619.

26. Felix C, Everaert B, Diletti R, et al. Current status of clinically available bioresorbable scaffolds in percutaneous coronary interventions. Neth Heart J. 2015;23:153-60.

27. Sijde JN van der, Regar E. Stent platforms anno 2015: is there still a place for bare metal stents at the front line? Neth Heart J. $2015 ; 23: 122-3$.

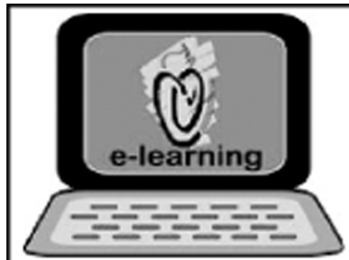

\section{CVOI E-learning formula!}

This is the CVOI e-learning article. The author has prepared 10 questions which are available through the website of the Cardiovascular Educational Institute (CVOI). Please follow the instructions below.

After finishing the questions you will be asked to fill in your name, hospital and e-mail address; then press the button 'verzenden'.

When 6 out of the 10 questions are answered correctly, you acquire 1 accreditation point granted by the Quality Committee of the Netherlands Society of Cardiology (NVVC). The acquired point will be credited to your personal file in the GAIA system. You will also receive an e-mail with all the correct answers.

Over a period of one year 10 e-learning articles will appear in 10 subsequent $\mathrm{NHJ}$ editions. In each edition the e-learning article will be recognisable by a special icon. On an annual basis you can collect 10 accreditation points. The accreditation points are credited in the GAIA system by the CVOI.

If you need additional information, please contact the CVOI by e-mail: cvoi@cvoi.org or by phone: 030-2345001.

E.E. van der Wall

Chief editor NHJ
K.B. Schick

Coordinator CVOI 